\title{
Falls and associated factors among elderly users of Primary Healthcare Services
}

\author{
Quedas e fatores associados em idosos usuários de serviços de Atenção Primária \\ à Saúde
}

\section{AUTHOR'S \\ Scarlet Feitosa Santos ${ }^{1}$ (D) \\ Miriane Lucindo Zucoloto ${ }^{1}$ \\ Natalia Akemi Yamada Terada ${ }^{1}$ (D) \\ Edson Zangiacomi Martinez ${ }^{1}$ (D) \\ 1 Universidade de São Paulo, Ribeirão Preto \\ Medical School. Ribeirão Preto, São Paulo, Brazil. \\ CORRESPONDING}

Edson Zangiacomi Martinez edson@fmrp.usp.br

Avenida Bandeirantes, 3900, Monte Alegre, Ribeirão Preto, São Paulo, Brasil.

CEP: 14049-900.

DOI

$10.12820 /$ rbafs. $23 \mathrm{e} 0052$

\section{(cc) BY-NC-SA}

This work is licensed under the Creative Commons Attribution-NonCommercial-ShareAlike 4.0 International License

\begin{abstract}
The objective of this cross-sectional study was to estimate the self-reported prevalence of falls among elderly users (older than 60 years) of the Ribeirão Preto, São Paulo, Brazil, primary healthcare services in the past six months and to identify associated factors. Data were collected from five healthcare districts by means of personal interviews with the users while they waited for the appointment. Log-binomial regression models adjusted for confounding variables and prevalence ratios were used to measure the association between independent and dependent variables. The International Physical Activity Questionnaire (IPAQ), adapted to elderly, was used to assess their physical activity. A total of 357 adults were interviewed, with $62.7 \%$ being women and mean age of 69.9 years old. The prevalence rates of falls in the past six months were $19.6 \%$ (95\% CI: $13.2-27.3)$ and $32.6 \%$ (95\%CI: 26.4-39.2), respectively, for men and women. The prevalence of falls among users with lower level of physical activity was 2.3 times higher than that among those with higher level of physical activity $(\mathrm{RP}=2.3 ; 95 \% \mathrm{CI}: 1.4-3.8)$ after adjustment for gender, age group and socio-economical class. In conclusion, falls are frequent among the elderly and the practice of physical activities can improve their health condition, thus preventing the occurrence of falls.
\end{abstract}

Keywords: Falls; Elderly; Observational study, Health services; Primary health care; Physical activities.

\section{RESUMO}

O objetivo deste estudo transversal foi estimar a prevalência autorreferida de quedas nos últimos seis meses em idosos (60 anos ou mais) usuários dos serviços de atenção primária à saúde de Ribeirão Preto, São Paulo, Brasil, e identificar os fatores associados. Os dados foram coletados nas cinco Unidades Básicas e Distritais de Saúde do município, por meio de entrevistas individuais face-a-face, enquanto os usuários aguardavam uma consulta. Modelos log-binomial de regressão ajustados as variáveis de confundimento e razóes de prevalência foram usadas como medidas de associação entre as variáveis independentes e as dependentes. Para avaliar do nivel de atividade física foi aplicado o Questionário Internacional de Atividade Física - IPAQ adaptado para idosos. Foram entrevistados 357 adultos (62,7\% mulheres, com idade média de 69,9 anos). A prevalência de quedas nos últimos seis meses foi de 19,6\% (IC95\%: 13,2-27,3) nos homens e de 32,6\% (IC95\%: 26,4-39,2) nas mulheres. Usuários com menor nivel de atividade física apresentaram prevalência de quedas 2,3 vezes maior comparada àqueles com elevado nivel de atividade física (RP = 2,3; IC95\%: 1,4-3,8), após ajuste para sexo, faixa etária e classe econômica. Em conclusão, as quedas são frequentes entre os idosos, e a prática regular de atividade física pode lhes proporcionar uma melhor condiçấo de saúde e uma menor ocorrência de quedas.

Palavras-chave: Quedas; Idosos; Estudo observacional; Serviços de saúde; Atenção Primária à Saúde; Atividade fisica.

\section{Introduction}

According to the World Health Organisation, approximately $28-35 \%$ of the worldwide population aged over 65 years old suffer from falls every year ${ }^{1}$. For elderly individuals aged 70 or older, these figures rise to $32-$ $42 \%{ }^{1}$. In Brazil, a study including more than 4,000 elderly individuals (over 60 years old) who lived in urban areas of 70 cities reported that $25.1 \%$ had suffered falls in the past 12 months prior to their interviews. Of these, $1.8 \%$ had fracture of femur or hip ${ }^{2}$. In addition, the mortality rates increased from 1.25 per 10,000 elderly in 1996 to 3.75 in $2012^{3}$. These figures evidence the need to develop healthcare techniques for the elderly as well as to adjust the health services and equipment to this population.

Considering that many elderly individuals live in 
non-adapted houses ${ }^{4,5}$, falls may occur, at least in part, due to extrinsic factors such as poor illumination, slippery floor, lack of stair handrail, uneven ground, obstacles inside the house, tall mattress or bed high off the ground, and loose carpets ${ }^{6-7}$. Nevertheless, the incidence of falls among the elderly is also associated with illnesses such as cerebrovascular accident, diabetes, heart disease, osteoporosis, depressive symptoms and arthritis ${ }^{5,8}$. Other causes include improper footwear, use of excessively long clothes, alcohol consumption, and use of medications ${ }^{9-12}$.

Among the consequences of falls, one can cite loss of independence, loss of autonomy and poor quality of life well as institutionalisation and impairment in the performance of social and daily activities ${ }^{8,13}$. A study assessing 399,681 elderly patients hospitalised due to falls between 2005 and 2010 showed that the total cost was estimated to be approximately $\mathrm{R} \$ 465$ million, with $59.7 \%$ of these expenses being for wom$\mathrm{en}^{16}$. Therefore, given the growing population of elderly people in Brazil and that a great portion of them benefit from the assistance provided by the national healthcare system, there is a need to carry out further studies to characterise these users of the primary healthcare services in order to guide preventive actions considering their peculiarities and demands ${ }^{14}$.

Two Brazilian studies of elderly patients attending the national healthcare system estimated the prevalence rates of falls in the cities of Natal (Rio Grande do Norte) and João Pessoa (Paraíba), with the former reporting $25.3 \%$ among men and $74.7 \%$ among women ${ }^{14}$ and the latter reporting $27.7 \%$ among men and $49.4 \%$ among women ${ }^{15}$. Therefore, the objective of the present study was to assess the prevalence of falls among elderly users of the primary healthcare services in the city of Ribeirão Preto (São Paulo), in the Southeastern Brazil, and to identify associated factors.

\section{Methods}

This is a cross-sectional study using a stratified sample of individuals aged 60 or older who lived in the city of Ribeirão Preto, State of São Paulo, and were users of primary healthcare services. The city of Ribeirão Preto has a territory of about $650 \mathrm{~km}^{2}$, harbouring a population estimated to be 694,000 in the year of $2018^{17}$. It is also estimated that 10.8 and $14.2 \%$ of elderly men and women are 60 years or older, respectively.

This study was approved by the local research ethics committee of the Ribeirão Preto School of Medicine of the University of São Paulo according to protocol number 1853261. All the participants signed an informed consent form.

The city of Ribeirão Preto is divided into five healthcare districts distributed in the north, west, central, south and east regions. These healthcare districts are defined as regions with areas and populations based on geographical, economic and social aspects seen in the several basic healthcare units, as defined by the Municipal Secretary of Health. Therefore, assuming that these healthcare units serve a population with heterogeneous socio-economic characteristics, but with less variability within their coverage areas, it was considered that each healthcare district represents a stratum. In each healthcare district, there are several basic healthcare units (BHUs) and a district basic healthcare unit (DBHU), which has a head office function. In addition to providing basic healthcare to its coverage area, the DBHUs also provide emergency services as well as specialty care such as gynaecology, obstetrics and paediatrics. Assuming that people attending a DBHU for basic healthcare services are also users of primary healthcare within the coverage area of the respective district, data were collected from each the five DBHUs. In this context, we have not considered people attending a DBHU for speciality care without first attending a BHU.

The total sample size was set to 357 users for a $95 \%$ confidence interval, $5 \%$ precision level and a priori prevalence of falls of $50 \%$ (i.e. a conservative value that maximises the sample size). The number of interviews in each DBHU was defined as being proportional to the mean number of elderly individuals seen in each unit - this information was provided the Municipal Secretary of Health. Overall, it is estimated that there are 2,510 appointments for elderly people in the DBHUs per month. Two interviewers were previously trained to apply the questionnaire to the users while they waited for their appointment and/or other healthcare services provided by the DBHU. The users were chosen based on a convenience sampling approach.

Elderly male and female participants aged 60 years or older were included in the study, all living in the city of Ribeirão Preto and using primary healthcare services. In order to avoid including individuals who attend DBHUs for some treatment out of the primary healthcare model, the questionnaire included the following question: "Do you use primary healthcare services?" Participants who are bedridden, mentally or physically handi- 
capped, or hospitalised were not including in the study.

The questionnaire elaborated for our study included the question "Did you have any fall in the past six months?" and also addressed age (in full years), school level (illiterate, primary, secondary and higher education), marital status (single, married, divorced or widowed), smoking habit (smoker, former smoker or non-smoker) and drinking habit (yes or no). In order to identify whether the participant is fully dependent on the healthcare system, the questionnaire asked whether he or she had a health insurance plan. Each participant was also asked to rate their perception of his or her health status as being good, fair or poor.

For evaluation of the physical fitness of the elderly participants, we have used the International Physical Activity Questionnaire (IPAQ) - adapted to elderly people - to address time spent in moderate/intense physical activities regarding work, transport, housework and leisure during a usual week ${ }^{19}$. The level of physical activity of each participant was rated as being high, moderate or low, according to the IPAQ scoring protocol ${ }^{20}$. Socio-economical class was addressed according to a criterion proposed by the Brazilian Association of Research Companies (ABEP ${ }^{21}$ based on the respondent's years of schooling and number of household goods, in which the purchasing ability of the respondent is rated according to social classes $\mathrm{A}, \mathrm{B} 1, \mathrm{~B} 2, \mathrm{C} 1, \mathrm{C} 2, \mathrm{D}$ and $\mathrm{E}$ in decreasing order. In the present study, the social classes A, B1 and B2 were combined for data analysis because there was a low frequency of respondents in social classes A and B1. The questionnaire also addressed the presence of blood pressure, diabetes, cholesterol or high triglycerides, osteoporosis, infarction, cerebrovascular accident (CVA), labyrinthitis, cancer and heart, respiratory, vascular and rheumatic diseases using the following question: "Have you ever been told by a doctor that you have/had .... (list of morbidities)?" Finally, an open-ended question was used to elicit physical and leisure activities the respondents were currently practicing.

Data analysis included estimation of the prevalence of falls in the past six months with their respective $95 \%$ confidence intervals $(95 \% \mathrm{CI})$, given by the exact method and using the binom.confint function of the $\mathrm{R}$ package software, version 3.4.3. The association between falls in the past six months and variables of interest was measured by using the prevalence ratio (PR), estimated with their respective 95\%CI based on log-binomial regression models ${ }^{22}$. When the $95 \% \mathrm{CI}$ for PR does not include 1, one has evidence of an association between the respective variable and the prevalence of falls (similar to $p<0.05$ ). Besides the crude values of $\mathrm{PR}$ for each variable (i.e. no adjustments for other variables), the estimation of PR was performed to measure the association between each variable and prevalence of falls adjusted for gender, age group and socio-economic class due to potential confounding factors involving such variables. The parameters of these regression models were estimated by using expectation-maximisation (EM) algorithms together with the log-bin package developed for $\mathrm{R}$ software by Donoghoe \& Marschner ${ }^{22}$.

As our objective was to find a set of variables in order to classify the respondents into two groups according to the occurrence or not of falls in the six past months, we have used a decision-tree algorithm (i.e. conditional inference tree $)^{23}$ together with the partykit $\mathrm{R}$ package $\mathrm{e}^{24}$ for doing so. The decision-tree representation consists of decision nodes representing classification rules based on a given variable and of terminal nodes describing the results of these classifications.

\section{Results}

A total of 357 elderly individuals were interviewed, with $62.7 \%$ being women and mean age of 69.9 years old. The participation rate in our study was $82.6 \%$. The mean ages for men and women were, respectively, 71.4 (standard deviation $=7.5$, range from 60 to 92 years) and 69.9 years old (standard deviation $=6.8$, range from 60 to 91 years). The prevalence of falls in the past six months was $27.7 \%$ (95\%CI: $23.2-32.7$ ), with $19.6 \%$ (95\%CI: 13.2-27.3) among men and 32.6\% (95\%CI: 26.4-39.2) among women.

Table 1 shows the prevalence rates of falls in the past six months according to demographic characteristics and health status of the elderly participants. The prevalence of falls among women was 1.7 times higher than that among men $(\mathrm{PR}=1.7 ; 95 \% \mathrm{CI}$ : 1.1-2.6) after adjustment for age group and socio-economic class. The prevalence of falls among the participants from classes $\mathrm{D}$ or $\mathrm{E}$ was approximately twice higher than that among those from classes $\mathrm{A}$ or $\mathrm{B}(\mathrm{PR}=1.8$; 95\%CI: 1.1-2.9). Among the elderly users having no health insurance plan, the prevalence of falls was twice higher than that of those who had it after adjustment for socio-economic class ( $\mathrm{PR}=2.0$; 95\%CI: 1.1-3.8). Among the participants with low level of physical activity, the prevalence of falls was 2.3 higher than that 
Table 1 - Prevalence of falls in the past six months according to the participants' characteristics. Ribeirão Preto, São Paulo, Brazil, 2018 (n = 357 ).

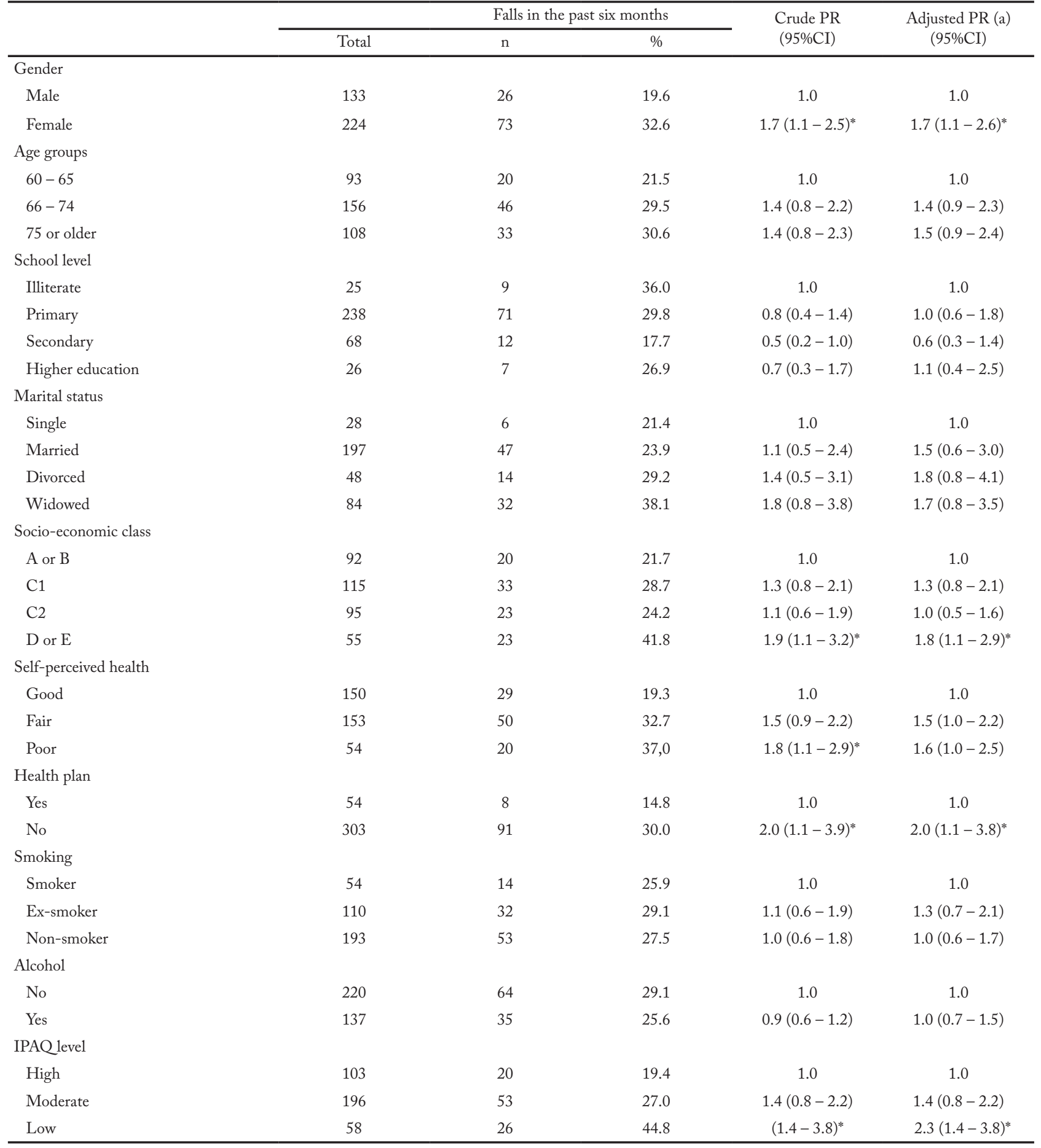

$\mathrm{a}=$ Prevalence ratio $(\mathrm{PR})$ adjusted for gender, age group and socio-economic class; ${ }^{*} \mathrm{p}<0.05$.

found for those with high level of physical actively (PR $=2.3 ; 95 \% \mathrm{CI}: 1.4-3.8)$ after adjustment for age group, gender and socio-economic class. There were no statistically significant associations between prevalence of falls and age group, education level, marital status, smoking and alcohol consumption.
It was observed that reports of falls were more frequently seen among elderly users who had vascular diseases and osteoporosis, but this association was not significant (Table 2). The gross association for self-reported gout was 1.6 (95\%CI: 0.6-3.7), increasing to 2.6 after adjustment for gender, age group and 
Table 2 - Prevalence of falls in the past six months according to self-reported morbidities. Ribeirão Preto, São Paulo, Brazil, 2018 ( $\mathrm{n}=357$ ).

\begin{tabular}{|c|c|c|c|c|c|}
\hline & \multicolumn{3}{|c|}{ Falls in the past six months } & \multirow{2}{*}{ Crude PR (95\%CI) } & \multirow{2}{*}{$\begin{array}{c}\text { Adjusted PR (a) } \\
(95 \% \mathrm{CI})\end{array}$} \\
\hline & Total & $\mathrm{n}$ & $\%$ & & \\
\hline \multicolumn{6}{|c|}{ Rheumatoid arthritis } \\
\hline No & 327 & 89 & 27.2 & 1.0 & 1.0 \\
\hline Yes & 30 & 10 & 33.3 & $1.2(0.7-2.1)$ & $1.1(0.6-1.9)$ \\
\hline \multicolumn{6}{|l|}{ CVA } \\
\hline No & 333 & 90 & 27.0 & 1.0 & 1.0 \\
\hline Yes & 24 & 9 & 37.5 & $1.4(0.8-2.4)$ & $1.4(0.7-2.3)$ \\
\hline \multicolumn{6}{|c|}{ Cancer } \\
\hline No & 330 & 91 & 27.6 & 1.0 & 1.0 \\
\hline Yes & 27 & 8 & 29.6 & $1.1(0.5-2.0)$ & $1.1(0.6-1.9)$ \\
\hline \multicolumn{6}{|c|}{ Diabetes } \\
\hline No & 264 & 71 & 26.9 & 1.0 & 1.0 \\
\hline Yes & 93 & 28 & 30.1 & $1.1(0.7-1.6)$ & $1.1(0.7-1.5)$ \\
\hline \multicolumn{6}{|c|}{ Heart diseases } \\
\hline No & 293 & 77 & 26.3 & 1.0 & 1.0 \\
\hline Yes & 64 & 22 & 34.4 & $1.3(0.8-1.9)$ & $1.3(0.8-1.9)$ \\
\hline \multicolumn{6}{|c|}{ Respiratory diseases } \\
\hline No & 315 & 90 & 28.6 & 1.0 & 1.0 \\
\hline Yes & 42 & 9 & 21.4 & $0.7(0.4-1.4)$ & $0.6(0.3-1.2)$ \\
\hline \multicolumn{6}{|c|}{ Vascular diseases } \\
\hline No & 308 & 79 & 25.6 & 1.0 & 1.0 \\
\hline Yes & 49 & 20 & 40.8 & $1.6(1.1-2.3)^{*}$ & $1.4(0.9-2.1)$ \\
\hline \multicolumn{6}{|c|}{ Fibromyalgia } \\
\hline No & 337 & 92 & 27.3 & 1.0 & 1.0 \\
\hline Yes & 20 & 7 & 35.0 & $1.3(0.6-2.4)$ & $1.1(0.6-2.0)$ \\
\hline \multicolumn{6}{|l|}{ Gout } \\
\hline No & 350 & 96 & 27.4 & 1.0 & 1.0 \\
\hline Yes & 7 & 3 & 42.9 & $1.6(0.6-3.7)$ & $2.6(1.4-4.6)^{*}$ \\
\hline \multicolumn{6}{|c|}{ Hypercholesterolemia } \\
\hline No & 258 & 65 & 25.2 & 1.0 & 1.0 \\
\hline Yes & 99 & 34 & 34.3 & $1.4(0.9-1.9)$ & $1.3(0.9-1.8)$ \\
\hline \multicolumn{6}{|c|}{ Blood pressure } \\
\hline No & 147 & 44 & 29.9 & 1.0 & 1.0 \\
\hline Yes & 210 & 55 & 26.2 & $0.8(0.6-1.2)$ & $0.8(0.5-1.1)$ \\
\hline \multicolumn{6}{|c|}{ Infarction } \\
\hline No & 325 & 89 & 27.4 & 1.0 & 1.0 \\
\hline Yes & 32 & 10 & 31.2 & $1.1(0.6-2.0)$ & $1.1(0.6-1.8)$ \\
\hline \multicolumn{6}{|c|}{ Labyrinthitis } \\
\hline No & 286 & 74 & 25.9 & 1.0 & 1.0 \\
\hline Yes & 71 & 25 & 35.2 & $1.4(0.9-2.0)$ & $1.4(0.9-2.0)$ \\
\hline \multicolumn{6}{|c|}{ Osteoporosis } \\
\hline No & 292 & 73 & 25.0 & 1.0 & 1.0 \\
\hline Yes & 65 & 26 & 40.0 & $1.6(1.1-2.3)^{*}$ & $1.2(0.8-1.8)$ \\
\hline \multicolumn{6}{|c|}{ Osteoarthritis } \\
\hline No & 289 & 81 & 28.0 & 1.0 & 1.0 \\
\hline Yes & 68 & 18 & 26.5 & $0.9(0.6-1.5)$ & $(0.5-1.3)$ \\
\hline
\end{tabular}

$\mathrm{a}=$ Prevalence ratio $(\mathrm{PR})$ adjusted for gender, age group and socio-economic class; ${ }^{*} \mathrm{p}<0.05$.

socio-economic class (95\%CI: 1.4-4.6). This result tio of 2.3 was adjusted only for this variable (95\%CI: shows an interaction with gender as the prevalence ra- 1.2-4.4). Among the participants suffering from gout, 
the occurrence of falls was reported by all women and by $20 \%$ of the men. Nevertheless, considering that the number of reports of gout is very low (only seven cases), the inferences on the possible association between gouts and falls were very limited.

Among the activities studied, only smartphone games were found to be associated with falls, even after adjustment for gender, age group and socio-economic class $(\mathrm{PR}=0.2 ; 95 \% \mathrm{CI}: 0.1-0.9)-$ Table 3. Of those participants reporting to play games on smartphones, $6.9 \%$ had falls, whereas of those who did not play such games, $26.6 \%$ had them.

Figure 1 shows the decision tree for classification of the participants into two groups, that is, those reporting falls in the past six months and those reporting no fall in the same period of time. Among the variables stud-

Table 3 - Prevalence of falls in the past six months according to physical and leisure activities. Ribeirão Preto, São Paulo, Brazil, 2018 (n = 357).

\begin{tabular}{|c|c|c|c|c|c|c|}
\hline & \multicolumn{4}{|c|}{ Falls in the past six months } & \multirow{2}{*}{ Crude PR $(95 \% \mathrm{CI})$} & \multirow{2}{*}{$\begin{array}{c}\text { Adjusted PR (a) } \\
(95 \% \mathrm{CI})\end{array}$} \\
\hline & \multicolumn{2}{|c|}{ Total } & \multirow{2}{*}{\multicolumn{2}{|c|}{$\%$}} & & \\
\hline \multicolumn{5}{|c|}{ Fitness gym } & & \\
\hline No & 340 & 97 & 28.5 & & 1.0 & 1.0 \\
\hline Yes & 17 & 2 & 11.8 & & $0.4(0.1-1.5)$ & $0.4(0.1-1.6)$ \\
\hline \multicolumn{7}{|l|}{ Walk } \\
\hline No & 269 & 77 & 28.6 & & 1.0 & 1.0 \\
\hline Yes & 88 & 22 & 25.0 & & $0.8(0.5-1.3)$ & $1.1(0.7-1.6)$ \\
\hline \multicolumn{7}{|c|}{ Sewing } \\
\hline No & 296 & 79 & 26.7 & & 1.0 & 1.0 \\
\hline Yes & 61 & 20 & 32.8 & & $1.2(0.8-1.8)$ & $1.0(0.6-1.6)$ \\
\hline \multicolumn{7}{|c|}{ Game of checkers } \\
\hline No & 344 & 98 & 28.5 & & 1,0 & 1.0 \\
\hline Yes & 13 & 1 & 7.7 & & $0.3(0.1-1.8)$ & $0.3(0.1-2.5)$ \\
\hline \multicolumn{7}{|c|}{ Dance } \\
\hline No & 338 & 97 & 28.7 & & 1.0 & 1.0 \\
\hline Yes & 19 & 2 & 10.5 & & $0.4(0.1-1.4)$ & $0.4(0.1-1.4)$ \\
\hline \multicolumn{7}{|c|}{ Aquarobics } \\
\hline No & 346 & 96 & 27.7 & & 1.0 & 1.0 \\
\hline Yes & 11 & 3 & 27.3 & & $1.0(0.3-2.6)$ & $0.9(0.3-2.4)$ \\
\hline \multicolumn{7}{|c|}{ Gardening } \\
\hline No & 324 & 89 & 27.4 & & 1.0 & 1.0 \\
\hline Yes & 33 & 10 & 30.3 & & $1.1(0.6-1.9)$ & $1.1(0.6-1.8)$ \\
\hline \multicolumn{7}{|c|}{ Card games } \\
\hline No & 328 & 95 & 29.0 & & 1.0 & 1.0 \\
\hline Yes & 29 & 4 & 13.8 & & $0.5(0.2-1.2)$ & $0.6(0.2-1.6)$ \\
\hline \multicolumn{7}{|c|}{ Smartphone games } \\
\hline No & 328 & 97 & 29.6 & & 1.0 & 1.0 \\
\hline Yes & 29 & 2 & 6.9 & & $0.2(0.1-0.9)^{*}$ & $0.2(0.1-0.9)^{*}$ \\
\hline \multicolumn{7}{|c|}{ Reading } \\
\hline No & 249 & 70 & 28.1 & & 1.0 & 1.0 \\
\hline Yes & 108 & 11 & 26.9 & & $0.9(0.6-1.4)$ & $1.0(0.6-1.4)$ \\
\hline \multicolumn{7}{|c|}{ Cross-word puzzle } \\
\hline No & 303 & 88 & 29.0 & & 1.0 & 1.0 \\
\hline Yes & 54 & 11 & 20.4 & & $0.7(0.4-1.2)$ & $0.6(0.3-1.2)$ \\
\hline \multicolumn{7}{|c|}{ Fishing } \\
\hline No & 348 & 98 & 28.2 & & 1.0 & 1.0 \\
\hline Yes & 9 & 1 & 11.1 & & $0.4(0.1-2.5)$ & $0.4(0.1-3.1)$ \\
\hline \multicolumn{7}{|c|}{ Painting } \\
\hline No & 332 & 93 & 28.0 & & 1.0 & 1.0 \\
\hline Yes & 25 & 6 & 24.0 & & $0.8(0.4-1.8)$ & $(0.3-1.4)$ \\
\hline
\end{tabular}

$\mathrm{a}=$ Prevalence ratio $(\mathrm{PR})$ adjusted for gender, age group and socio-economic class; ${ }^{*} \mathrm{p}<0.05$. 

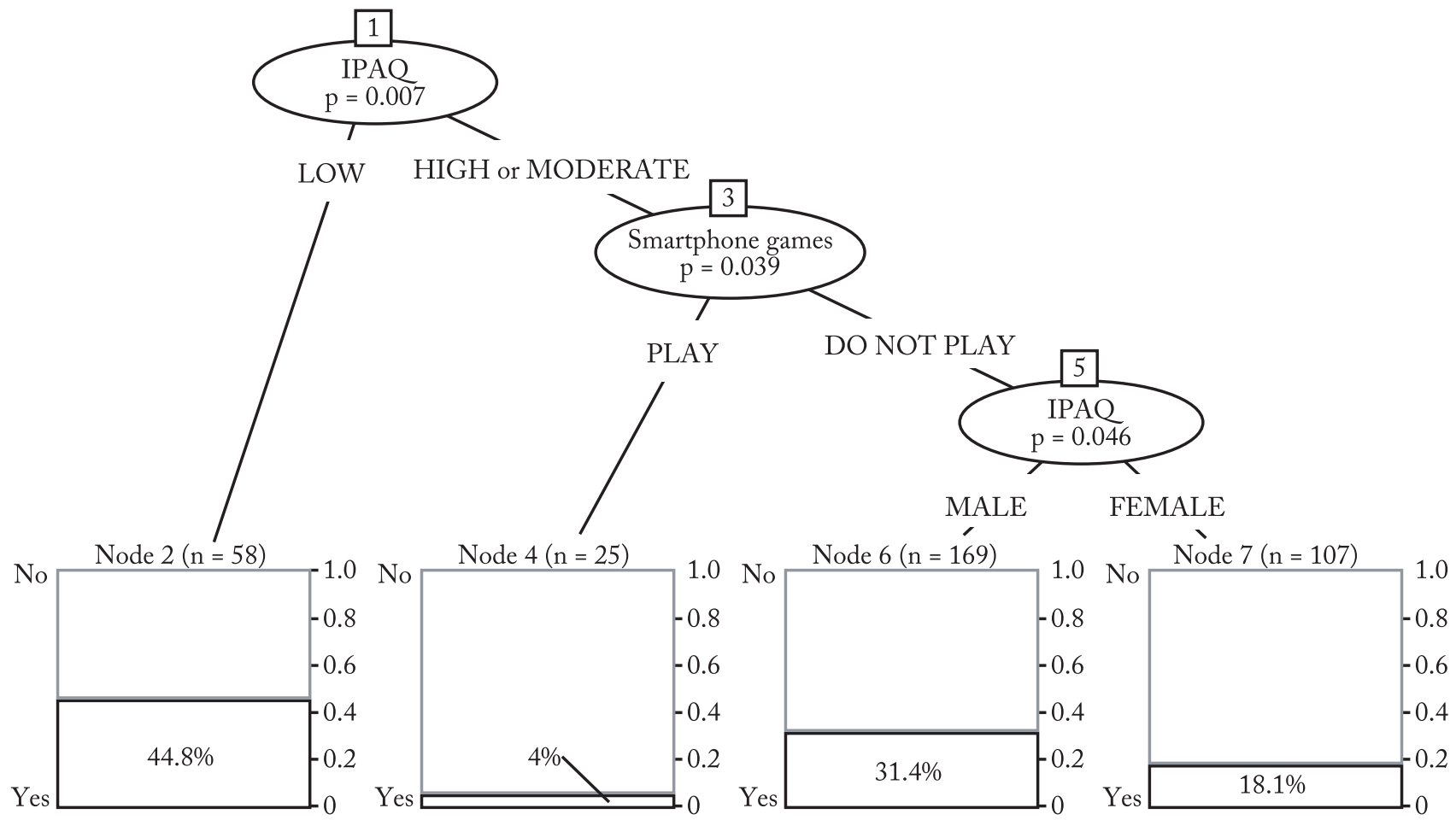

Figure 1 - Decision tree for classification of participants who reported or did not report falls in the past six months. Ribeirão Preto, São Paulo, Brazil, 2018 ( $\mathrm{n}=357)$.

ied, the classification algorithm selected level of physical activity, smartphone games and sex. Decision nodes are oval representations (Figure 1) with their respective $\mathrm{P}$-values, whereas terminal nodes are rectangles shown in the lower part of the figure in which the part with dark border corresponds to the porcentage age of participants who reported falls in that classification pathway. Among the participants with low physical activity, $44.8 \%$ reported falls (according to terminal node 2). On the other hand, among those with high or moderate physical activity and who play games on smartphones, one can observe a lower frequency of falls, that is, only $4 \%$ (according to terminal node 4). Among the participants with high to moderate physical activity but who do not play games on smartphones, the frequency of falls ranged according to gender (decision node 5), that is, $31.4 \%$ among women (terminal node 6) and $18.1 \%$ among men (terminal node 7) had falls.

\section{Discussion}

The prevalence of falls in the past six months was $27.7 \%$, with $19.6 \%$ being men and $32.6 \%$ being women. These estimations are very close to those reported in a nationwide study by Pimentel et al. ${ }^{2}$, who found $18.4 \%$ among men and $30.2 \%$ among women, although the authors have considered falls in the past 12 months. In addition, an integrative literature review of 35 studies showed that the prevalence of falls among elderly people living in different cities of Brazil ranged from 10.7 to $59.3 \%$, considering the 12 -month period before the interview ${ }^{25}$. This variation, despite the possible effect of different sampling methods and the operational definition of the variable of interest (i.e. falls), suggests that specific characteristics of each region may be related to the occurrence of falls. In any case, these figures evidence the high prevalence of falls among elderly people in Brazil and the relevance of healthcare strategies for prevention and rehabilitation.

The prevalence of falls was higher among women, a finding corroborated by other studies ${ }^{10-15}$. Nevertheless, the mechanisms explaining this association are unclear. Some authors state that women have less lean body mass and less muscle force compared to men, including a greater loss of bone mass as result of the reduction in estrogen levels.

Falls occurring in the past six months were more frequent among the participants from lower socio-economic classes D and E (41.8\%) compared to those from higher classes A and B (21.7\%, p < 0.05). This association with socio-economic class was also found elsewhere $^{2.5}$ and can be explained by differences in healthcare access and nutritional aspects. One can also observe a higher prevalence of falls among elderly peo- 
ple who have no health insurance plan (Table 1), which reinforces the importance of organising the actions provided by practitioners who work in primary healthcare units and family healthcare services. Prato et al. ${ }^{26}$ suggested the following actions: to encourage the practice of physical activities for muscle strengthening, to promote continuous education on environmental risks and risk attitudes within the context of aging, and to identify individuals at risk of falls. In this sense, it is estimated that $52 \%$ of the urban population of Ribeirao Preto use only the public healthcare system, whereas $80 \%$ use it occasionally ${ }^{27}$.

A univariate analysis has shown that the prevalence of vascular diseases and osteoporosis was associated with falls. Vascular diseases can lead to decrease in the cerebral blood flow, cognitive decline and bone mass reduction, thus making elderly individuals vulnerable. As a whole, these factors can contribute to a higher risk of falls. However, the respective estimates adjusted for gender, age group and socio-economic status do not confirm such associations. In addition, the fact that these morbidities were self-reported and that the hypothesis may not have been adequately tested due to the sample size are limitations to be considered.

In Table 1, one can observe that $19.4 \%$ of the participants performing high physical activity suffered falls in the last six months, whereas $44.8 \%$ of those having low physical activity had falls. It is known that loss of muscle strength results in impairment to activities requiring moderate effort, thus causing the elderly to be more dependent and favouring falls ${ }^{28}$. In addition, physical activity improves postural stability and gait of elderly individuals, which can reduce the chance of falls ${ }^{28}$. Among the participants having high to moderate levels of physical activities, smartphone games would have some significant association with absence of falls (Figure 1). Among the 25 participants with these characteristics, only $4 \%$ reported falls in the past six months (Figure 1). This result does not suggest that games have some preventive effect on falls, but Wilmer et al. ${ }^{29}$ demonstrated that smartphones are associated with an increase in the cognition of elderly people when used judiciously. In this way, according to our data analysis, the effect of smartphone games is likely due to some cognitive skill elderly individuals have, which in turn is related to a reduction in the chance of falls.

Among the limitations of the present study, one can cite its cross-sectional nature, which impedes causal inferences. The results may be subject to memory bias as the participants were asked to report events of falls in the past six months before the interviews. Other important bias may be the fact that we have used prevalent cases, which excludes deaths resulting from falls as well as cases resulting in hospitalisation or impeding participation in the study. A higher number of women were interviewed $(62.7 \%)$ in our study, which is due to the longer longevity of women and to the less search for primary healthcare by men ${ }^{30}$. The convenience sampling approach to recruit elderly people in the waiting rooms can also bring biases to our results. Moreover, the instrument used for data collection did not include important information, such as number of falls, site of falls and possible occurrence of fracture as a result of the fall. Nevertheless, our results reinforce the important role played by interdisciplinary healthcare teams who work in the primary healthcare units in the prevention of fall among the elderly population.

In conclusion, the present study has shown evidence that falls are frequent among the participants and the regular practice of physical activity can improve their health conditions, thus reducing the occurrence of falls.

\section{Conflict of interest}

The authors declare no conflict of interest.

\section{Authors' contributions}

Santos SF, was responsible for the literature search, data collection, writing of the manuscript, and critical analysis and revision of the text. Zucoloto ML, was involved in the protocol development and critical analysis and revision of the text. Terada NAY, was responsible for the literature search, data collection, writing of the manuscript, and critical analysis and revision of the text. Martinez EZ, was involved in the protocol development, statistical analysis of data, writing of the manuscript, and critical analysis and revision of the text.

\section{Acknowledgements}

This study received financial support from São Paulo Research Foundation - FAPESP, grant \#2016/14983-4.

\section{References}

1. World Health Organization. WHO Global Report on falls prevention in older age. United States of America: WHO; 2007.

2. Pimentel WRT, Pagotto V, Stopa SR, Hoffmann MCCL, Andrade FBD, Souza PRBD, et al. Falls among Brazilian older adults living in urban areas: ELSI-Brazil. Rev Saude Publica. 2018;52(Suppl 2):12s.

3. Abreu DROM, Novaes ES, Oliveira RR, Mathias TAF, Marcon SS. Fall-related admission and mortality in older adults in Brazil: trend analysis. Cien Saude Colet. 2018;23(4):1131-41. 
4. Oliveira MJS, Santos F, Lange C, Casagranda LP, Thumé E, Castro DSP. Accidents due to falls and femoral fracture in elderly population. Rev Enferm UFSM. 2018;8(2):225-35.

5. Vieira LS, Gomes AP, Bierhals IO, Farías-Antúnez S, Ribeiro CG, Miranda VI, et al. Falls among older adults in the South of Brazil: prevalence and determinants. Rev Saude Publica. 2018;52:22.

6. Neto JAC, Braga NAC, Brum, IV, Gomes GF, Tavares PL, Silva RTC, et al. Awareness about falls and elderly people's exposure to household risk factors. Cien Saude Colet. 2018;23(4):1097-104.

7. Oliveira AS, Trevizan PF, Bestetti MLT, Melo RC. Environmental hazards and risk of fall in the elderly:systematic review. Rev Bras Geriatr Gerontol. 2014;17(3):637-45.

8. Alves RLT, Silva CFM, Pimentel LN, Costa IA, Souza ACS, Coelho LAF. Evaluation of risk factors that contribute to falls among the elderly. Rev Bras Geriatr Gerontol. 2017;20(1):59-69.

9. Arruda GT, Strelow CS, Weschenfelder ÁJ, Froelich MA, Foletto Pivetta HM, Braz MM. Comparing the risk of falls between rural and urban elderly. Acta Sci Health Sci. 2018;40(1):e33449.

10. Cruz FMD, Chaoubah A, Cruz DTD, Leite ICG. Factors associated with recurrent falls in a cohort of elderly people. Cad Saúde Coletiva. 2017;25(4):475-4.

11. Rosa BM, Abreu DPG, Santos SSC, Silva BT, Ilha S, Martins NFF. Association between fall risks and medication use in the elderly. Rev Baiana Enferm. 2018;31(4):e22410.

12. Rodrigues IG, Fraga GP, Barros MBA. Falls in the elderly: risk factors in population-based study. Rev Bras Epidemiol. 2014;17(3):705-18.

13. Vieira KFL, Baía RV, Lucena ALR, Delgado ART, Oliveira LB. Prevalence and concern to the risk of falls in community elderly people. Rev Enferm UFPE on line. 2017;11(1):351-7.

14. Santos RKMD, Maciel ACC, Britto HMJDS, Lima JCC, Souza TOD. Prevalence and factors associated with the risk of falls among the elderly registered in a primary healthcare unit of the city of Natal in the state of Rio Grande do Norte, Brazil. Cien Saude Colet. 2015;20(12):3753-62.

15. Dantas EL, Brito GEG, Lobato IAF. Prevalence of falls in elders ascribed to the family health strategy of the city of João Pessoa, Paraíba. Rev APS. 2012;15(1):67-75.

16. Barros IFO, Pereira MB, Weiller TH, Anversa ETR. Hospitalizations due to falls among elderly Brazilians and related costs under the Public Health System. Rev Kairós. 2015;18(4):63-80.

17. Instituto Brasileiro de Geografia e Estatística: Brasil em Síntese. Brasília: IBGE; 2019. [cited 2019 feb 6]. Available at: https://cidades.ibge.gov.br/.
18. Scheaffer RL, Mendenhall III W, Ott RL, Gerow KG. Elementary Survey Sampling. Boston: Cengage Learning, 2011.

19. Benedetti TB, Mazo GZ, Barros MV. Application of the International Physical Activity Questionnaire (IPAQ) for evaluation of elderly women: concurrent validity and testretest reprodutibility. Rev Bras Ciênc Mov. 2008;12(1):25-34.

20. Guideline for Data Processing and Analysis of the International Physical Activity Questionnaire (IPAQ). IPAQ Group; 2005. [cited 2019 feb 6]. Available at: http://www. ipaq.ki.se.

21. Associação Brasileira de Empresas de Pesquisa: Critério Brasil 2018. São Paulo: ABEP; 2018. [cited 2019 feb 6]. Available at: http://www.abep.org/.

22. Donoghoe MW, Marschner IC. logbin: An R Package for relative risk regression using the log-binomial model. J Stat Softw. 2018;86(1):1-22.

23. Hothorn T, Hornik K, Zeileis A. Unbiased recursive partitioning: A conditional inference framework. J Comput Graph Stat. 2006;15(3):651-74.

24. Hothorn T,Zeileis, A. partykit: A modular toolkit for recursive partytioning in R.J Mach Learn Res. 2015;16(1):3905-9.

25. Leitão SM, Oliveira SC, Rolim, LR, Carvalho RP, Filho JMC, Junior AAP. Epidemiology of falls in older adults in Brazil: an integrative literature review. Geriatr Gerontol Aging. 2018;12(3):172-9.

26. Prato SCF, Andrade SM, Cabrera MAS, Dip RM, Santos HG, Dellaroza, MSG, et al. Frequency and factors associated with falls in adults aged 55 years or more. Rev Saude Publica. 2017;51:37.

27. Prefeitura Municipal de Ribeirão Preto. Fatores de risco relacionados à saúde da população residente na zona urbana de Ribeirão Preto (SP), 2008-2011. Ribeirão Preto; 2011.

28. Pedrinelli A, Garcez-Leme LE, Nobre RSA. The effect of physical training on locomotive apparatus in elderly people. Rev Bras Ortop. 2009;44(2):96-101.

29. Wilmer HH, Sherman LE, Chein JM. Smartphones and cognition: A review of research exploring the links between mobile technology habits and cognitive functioning. Front Psychol. 2017;8:605.

30. Barbosa YO, Menezes LPL, Santos JMJ, Cunha JOD, Menezes AF, Araújo DDC, et al. Access of men to primary health care services. J Nurs UFPE. 2018;12(11):2897-905.

Received: $17 / 10 / 2018$

Approved: 11/03/2019 